\title{
The Effectiveness of Internet Based Cognitive Behavior Therapy on Reducing Anxiety in STIBA X Students
}

\author{
Nafisah, Helly Weliangan \\ 1995ichanafisah@gmail.com \\ Postgraduate Faculty of psychology Gunadarma University \\ J1. TB Simatupang No.51B, RT.1/RW.8, Jati Padang \\ Email hellyweliangan94@gmail.com \\ Postgraduate Faculty of psychology Gunadarma University \\ J1. TB Simatupang No.51B, RT.1/RW.8, Jati Padang
}

\begin{abstract}
STIBA (Arabic Language College) "X" is a high school that teaches Arabic and the Qur'an. STIBA "X" aims to produce superior, competitive and professional educators in the Arabic language field. STIBA "X" is a school that has high competition and implements a drop out system to maintain the quality and quality of its students. This drop out system makes students feel worried and anxious in their studies. Based on the results of interviews, it was found that STIBA "X" students had moderate to high anxiety. The purpose of this study was to examine the effectiveness of iCBT therapy in reducing anxiety in STIBA "X" students. The subjects of this study were 20 STIBA students who had moderate and high levels of anxiety. Anxiety levels were measured using BAI (Beck Anxiety Inventory) with a reliability of 0.875 . The 20 students were divided into an experimental group and a control group using a randomized technique. The research data was taken using the pre-test and post-test methods. Hypothesis testing was carried out using the independent paired T-test method. From the results of the independent paired T-test, a significance result of 0.000 was obtained with a mean difference of 12.50, this shows that the iCBT therapy given is effective in reducing anxiety in STIBA "X" students.
\end{abstract}

Keyword: Anxiety; iCBT college students

\section{INTRODUCTION}

(STIBA (High School of Arabic Language) $\mathrm{X}$ is an Islamic boarding school with a university level that aims to teach Arabic and the Qur'an. STIBA X is open to students and graduates from Islamic boarding schools and public schools. To maintain the quality of its students, STIBA X implements a drop out system. Students who do not pass in some subjects will be dropped out. This drop out system is implemented at the end of every semester (Araayah, 2020). STIBA also has a high level of competition. Students try to study hard every single day to avoid being dropped out. This drop out system can motivate and be a pressure for students. Students feel motivated by the drop out system and become more diligent in studying. However, some 
students feel anxious about the drop out system. Students are anxious when they cannot understand the lesson or having difficulty in class and fail in exams. This anxiety then affects the academic performance of STIBA students.

Based on the results of interviews with STIBA X students, it was found that many STIBA X students were anxious about the drop out system. According to Beck (2010) anxiety is an emotional response that is triggered by fear. In other word anxiety is a state of unpleasant feeling that is evoked when fear is stimulated. The fear that arises because of the heavy learning system and the drop out system makes students feel anxious. This anxiety causes many students to experience problems such as difficulty concentrating, difficulty sleeping, loss of appetite. From the explanation above, it can be seen that students experience the effects of anxiety. Beck (2010) divides some of the effects of anxiety, namely cognitive, physical and behavioural. The perceived anxiety affects students both in terms of cognitive, physical and behavioural. The higher the anxiety felt, the more obvious the effects of that anxiety will be. The effects of this anxiety can impact the academic performance of STIBA X.

To help STIBA X students reduce their anxiety, researchers devised an intervention to help reduce their anxiety. The intervention method used in this research is CBT (cognitive behavior therapy). According to Judith Beck (2011), CBT therapy is therapy that is based on the conceptualization, or understanding, of patients (their specific beliefs and behavior patterns). The intervention is based on Beck's (1979) theory of 5 skills learned in CBT therapy. The skills taught are as follows: subject understands how to monitor negative thoughts that arise when anxious, subject can recognize the relationship between cognition, affect, and behavior. subject can identify the anxiety they have based on the symptoms of anxiety they have, subject can replace biased and anxiety-producing thoughts with positive thoughts and, and subject can understand how to identify and change beliefs that can lead to anxiety.

Due to COVID-19, the Ministry of Education and Culture has implemented a regulation as a guideline for implementing learning in 2020/2021 during the COVID-19 pandemic. The new regulation states that schools and universities are prohibited from conducting face-to-face learning processes and continuing to carry out learning from home. The new regulation exist to reduce contact and prevent the spread of COVID-19 in accordance with the regulation from the Ministry of Education and Culture. In STIBA X several students, especially those in the third and fifth semesters, attend online lectures. This is done to reduce the number of students at STIBA. Lectures are carried out using google meet and assignments are sent using email, google doc, what's up and other online media.

To anticipate the current COVID-19 situation, CBT intervention will be provided remotely by using the internet. The therapist will provide therapy to students using internet media or internet based cognitive behaviour therapy (iCBT). CBT carried out using the internet has often been applied in CBT research. One of them is a study conducted by Andrews, Basu, Cuijpres, Craske, McEvoy, English and Newby (2018) regarding the effectiveness of iCBT (Internet Based Cognitive Behaviour Therapy) therapy to overcome anxiety and depression. In this study, researchers found that iCBT therapy was very effective in treating anxiety and depression in patients.

From the explanation above, it can be concluded that the STIBA X drop out system can cause anxiety in students, where this anxiety has an impact on cognitive, emotional and behaviour which ultimately affects student academic performance. The decline in academic performance can make students being drop out of STIBA X. To help reduce the level of anxiety in students, researchers developed a CBT intervention. However, due to the COVID situation, the intervention was provided via the internet or by using iCBT. 


\section{RESEARCH METHOD}

The research was conducted using a true experimental design in the form of pre-test and post-test. The research subjects were 20 students from STIBA X. The research subjects were selected using a purposive sampling method with the following criteria for screening: they are a 3rd semester student of STIBA X, came from public schools, had mild and high levels of anxiety, and were willing to take part in the intervention. until finish. 20 subjects were divided into a control group and an experimental group using the randomization method. The experimental group and the control group received a pre-test to determine the mean value of the group before being given therapy. After that the experimental group received therapy while the control group did not receive therapy.

iCBT therapy consists of 6 sessions for 3 weeks using google meet as an intermediary medium. The interventions provided consisted of psychoeducation, exercises, discussions and homework. After the therapy was completed, both groups were given a post-test to test the significance of the difference in the mean scores between the two to see the effect of iCBT therapy given to the experimental group. The therapy design was carried out 6 times in a row in a span of 50-55 minutes for each meeting. Therapy sessions are arranged based on the stages of therapy from Beck (1979). intervention sessions in this study consisted of psychoeducation, discussion, exercises, and homework.

The instrument used in this study was an anxiety scale adapted from BAI (Beck, et al. 1998) which was compiled based on the anxiety aspects of Beck (2010). Before the anxiety scale was given to the subject, a try out was carried out first. The content validity test was carried out with the assistance of the supervisor, to ensure that the sentences used in the anxiety scale could be understood and could measure anxiety. In addition, based on the discrimination power test, the results showed that 5 items from the anxiety scale had a coefficient value below 0.3 . These five items are eliminated. The final anxiety scale consists of 16 items and has a correlation range between 0.365 to 0.665 . based on the reliability test obtained a value of 0.864 . With a reliability of 0.864 which is greater than $\mathrm{P}>0.75$. This shows that the anxiety scale is reliable.

\section{RESULT AND DISSCUSION}

The research was conducted using a true experimental design. In this research design, there are experimental group and control group. The experimental group received CBT therapy while the control group did not. However, both groups received pre-test and post-test before and after the therapy was given. iCBT therapy was held for 6 sessions using google meet.

Before testing the hypothesis, the assumption is tested first to find out whether or not normality and homogeneity in the distribution of data are met or not. The normality test in this study used the Shapiro-Wilk technique with the help of SPSS. By using the Shapiro-Wilk technique, the normality of the pre-test and posttest in the experimental group and the control group was tested. The following are the results of the normality test from the experimental group:

Table 1: The results of the normality test of the experimental group

\begin{tabular}{llll}
\hline & \multicolumn{2}{l}{ Shapiro-Wilk } & \\
& Statistic & df & Sig. \\
\hline Pre-Test & .910 & 10 & .284 \\
Post-Test & .951 & 10 & .678 \\
\hline
\end{tabular}

Based on table 1, it can be seen that the pre-test experimental group has a significant value of 0.284 while the post-test has a significant value of 0.678 . The significant value of the pre-test and post-test has a value 
above $\mathrm{p}>0.05$, so it can be concluded that the pre-test and post-test data for the experimental group are normally distributed. The following table is the results of the normality test from the control group.

Table 2: Normality test results for the control group

\begin{tabular}{llll}
\hline & \multicolumn{2}{l}{ Shapiro-Wilk } & \\
& Statistic & df & Sig. \\
\hline Pre-Test & .879 & 10 & .127 \\
Post-Test & .881 & 10 & .133 \\
\hline
\end{tabular}

Based on table 2, it can be seen that the pre-test experimental group has a significant value of 0.127 while the post-test has a significant value of 0.133 . The significant value of the pre-test and post-test has a value above $\mathrm{p}>0.05$, so it can be concluded that the pre-test and post-test for the experimental group are normally distributed.

In addition, a homogeneity test was also conducted for the pre-test and post-test groups of the experimental group and the control group. The homogeneity test was carried out to ensure that the research subjects came from the same group, the homogeneity test was carried out using the Levene test. The results of the homogeneity test are as follows:

Table 3: Homogeneity test results

\begin{tabular}{llll} 
Pre-test & & & \\
\hline Levene Statistic & df1 & df2 & Sig. \\
\hline .008 & 1 & 18 & .931 \\
\hline
\end{tabular}

\begin{tabular}{llll} 
Post-test & & & \\
\hline Levene Statistic & df1 & df2 & Sig. \\
\hline .460 & 1 & 18 & .506 \\
\hline
\end{tabular}

Based on table 3, it can be seen that the pre-test results have a significant value of 0.931 while the post-test has a significant value of 0.506 . The significant value of the pre-test and post-test has a value above $p>0.05$, so it can be concluded that the data variance of the control and experimental groups is the same or homogeneous.

Hypothesis testing was carried out using the independent paired T-test to test the significance of the difference in the mean values of two different groups from the control group and the experimental group. From the results of the hypothesis test, it is known that there is a significant difference between the anxiety scores in the control group and the experimental group with a significance value of 0.000 and a mean difference of 12.50. This shows that the iCBT therapy given can reduce anxiety levels in STIBA students. The results of hypothesis testing can be seen in table 4:

Table 4: the results of hypothesis testing

\begin{tabular}{llllll}
\hline 4. Variabelle & 5. Group & 6. Maen & $\begin{array}{l}\text { 7. Maen } \\
\text { difference }\end{array}$ & 8.t & 9. Sig. \\
\hline 10. Anxiety & 11. experiment & 12.23 .90 & 13. & 14. & 15. \\
& 16. control & 17.36 .40 & 12.50 & 5.014 & 0.000 \\
\hline
\end{tabular}

In addition, the decrease in anxiety in STIBA students can be seen from the results of the pre-test and posttest of the experimental group and the control group. The results of the pre-test and post-test from the control group and the experimental group were divided into three categories, namely low, moderate and high. Anxiety 
categories are divided based on the BAI scale (Beck, 2010). From these categories, it can be seen in the pretest results of the experimental group that 7 subjects were in the high category and 3 subjects were in the moderate category. After receiving iCBT therapy, in the post-test results of the experimental group, 6 subjects were in the moderate category and 4 subjects were in the low category. From these results, it can be seen that iCBT is effectiveness in reducing anxiety levels on subject.

To see the decrease in subject's anxiety levels in each therapy session, researchers gave a daily anxiety level scale to subjects before the intervention session began. Anxiety scale consists of numbers 1-10, subject is tasked to fill in the level of anxiety they feel on that day based on a scale of 1-10. This anxiety scale is used to see how subject's level of anxiety in each intervention session. The level of anxiety in the subject was high when the intervention started, but as the intervention session progressed it could be seen that student's anxiety level decreased on each session. At the end of the intervention, subject's anxiety level was lower than when the intervention started. From these results, it can be seen how the iCBT therapy given can help reduce anxiety in subject at each session.

From the explanation above, it can be seen that iCBT therapy can reduce anxiety in STIBA X students. The results of previous studies are the same as those of previous studies conducted by Ezegbe, Eseadi, Ede, Igbo, Anyanwu, and Ede (2019). The results of this study, researchers wanted to examine the effect of CBT therapy on anxiety and depression. The results showed that CBT therapy can reduce anxiety and depression.

Further research was carried out by Anna, Giusti, Ussorio, Casacchia, and Roncone (2020), in this study conducted to examine the differences between online CBT therapy and face-to-face CBT therapy. In this study, it was found that group therapy conducted online had the same results as face-to-face therapy. This shows that CBT therapy carried out using a computer can help reduce anxiety as CBT therapy is done face-toface. In addition, there is also research conducted by Schnider, Hadjistravropoulos, Dear, and Titov (2020) regarding iCBT therapy. This study was conducted to examine the use of intervenes iCBT to reduce depression and anxiety in patients with heart problems during COVID-19. From this study it was found that iCBT therapy can help reduce levels of depression and anxiety in patients with heart problems. From the studies above, it can be concluded that although iCBT therapy has the same results as CBT that is carried out face-to-face.

Researchers conducted an evaluation questionnaire to find out how the subjects reacted to the intervention they had received. This evaluation assesses how the researcher performs in providing interventions, delivering materials, providing exercises and homework, and how the subjects think about the interventions provided via the internet. Based on the results of the questionnaire evaluation, the subject had a good reaction to the intervention given. Subject felt that the researcher could convey the intervention materials well. Subject also felt that the researcher could explain the exercises and homework well. Subjects' assessment of the intervention provided via the internet was not the same. Some subjects feel that intervention with internet media is very good, but some of them feel that intervention through internet media is normal, this is due to the obstacles that arise as a result of internet connection disturbances. Overall, subjects had a good assessment of the iCBT in this study.

Researchers also conducted interviews to determine the results of therapy based on qualitative. by conducting interviews with research subjects, researchers got the results that the therapy given can help subject overcoming the anxiety problems they have. Subjects felt that the materials and exercises provided could be applied outside of therapy to help friends or family when they were anxious. In addition, subject also feels that the material and exercises provided can be taught to friends or family. Subjects can understand the importance of positive thinking and how positive thinking can challenge their anxiety. The input and criticism in this therapy is how the researcher conveys the therapy material. Subject felt that the researcher was monotonous in presenting the material. The suggestion is to use video media so that the material provided is 
not monotonous and more interesting. Subject also suggested that a private therapy session be made so that the subject could be more open when talking about their anxiety problems.

From the discussions above, it can be seen that the iCBT intervention can help reduce anxiety on research subjects. This can be seen from the results of the hypothesis test, the results of the pre-test and post-test given and the results of the daily anxiety scale. Based on the results of the evaluation, it can be seen that the research subjects can understand the material and the exercises provided, besides that the research subjects also have a good assessment of the training as a whole. From the results of the interviews, it can be seen that overall the research subjects felt that the therapy provided could help them overcome their anxiety problems. Subjects can apply the exercises they have done to help reduce anxiety and teach them to friends and family.

\section{CONCLUSION AND SUGGESTION}

Based on the results of hypothesis testing, significant results were obtained, this indicates that the iCBT intervention given can help subject reduce their anxiety levels. In addition, the decrease in anxiety in the subject can also be seen from the decrease in the daily scale results in each therapy session. Based on the results of the pre-test and post-test of anxiety, it can be seen that there is a decrease in anxiety after and before iCBT therapy is given, this can be seen from the decrease in the category of the subject's anxiety value. Subjects who had anxiety in high category decrease to moderate, and subjects who had anxiety in high category decrease to low. Based by the interview with subjects it show that the iCBT therapy given could help subject in overcoming their anxiety problems. Subjects can understand how negative thoughts can lead to anxiety and the importance of positive thinking.

The advice given for further research is to add an observer in the study so that the effectiveness of the intervention can increase and reduce subjectivity. Further research can also be carried out with different populations or samples to see whether the research conducted can be generalized or not. In addition, interventions can also be carried out with the help of psychologists who have experience in providing interventions to reduce bias in research.

\section{REFERENCES}

Anna, S. Giusti, L. Ussorio, D. Casacchia, M. Roncone, R. (2020). Cognitive behavioral therapy (CBT) anxiety management and reasoning bias modification in young adults with anxiety disorders: A real-world study of a therapist-assisted computerized (TACCBT) program Vs. "person-to-person" group CBT. Internet Intervention. Vol.19:

Andrews, G. Basu, A. Cuijpres, P.Craske, M.G. McEvoy, P. English, C.L. Newby, J.M. (2018). Computer therapy for the anxiety and depression disorders is effective, acceptable and practical health care: An updated meta-analysis. Journal of Anxiety Disorders. Vol 55: $70-78$.

Arayaah. (2020). Pedoma akademik sekolah tinggi Bahasa Arab tahun ajaran 2020-2021. Sukabumi: STIBA Arayaah

Beck, A.T. Rush, A.J. Shaw, B.F. Emery, G. (1979). Cognitive therapy of depression. New York: Guilford.

Beck, A. T., Epstein, N., Brown, G., \& Steer, R. A. (1988). An inventory for measuring clinical anxiety: psychometric properties. Journal of Consulting and Clinical Psychology. Vol. 56: 893-897.

Beck, A.T. Clark, D.A. (2010). Cognitive therapy of anxiety disorders science and practice. New York: Guilford.

Beck, J. S. (2011). Cognitive behavior therapy: basics and beyond (2nd edition.). New York: Guilford.

Calik, M. (2020). Determining the anxiety and anxiety levels of university students in the covid 19 outbreak.: university students in the covid 19 outbreak. International Journal of Medical Science and Clinical Invention. Vol.7(7): 4887-4894.

Ezegbe, B. Eseadi, C. Ede, M.O. Igbo, J.N. Anyanwu, J.I. Ede, K.R. (2019). Impacts of cognitive-behavioral intervention on anxiety and depression among social science education students. Journal of Medicine. Vol. 98(15).

Schneider, L.H. Hadjistravropoulos, H.D. Dear, B.F. Titov, N. (2020). Efficacy of internet-delivered cognitive behavioural therapy following an acute coronary event: A randomized controlled trial. Internet Intervention. Vol.21. 